to bind tightly to DNA. One action of 9-cis-retinoic acid is to promote the formation of RXR homodimers that bind to a number of retinoid response elements ${ }^{18}$, although none appears to be specific for RXR homodimers. In the case of heterodimers, RXR may act simply as an adapter to allow other receptors to bind specifically to their response elements. However, in addition, RXR could contribute to the trans- response. A possible function of such a mechanism would be to control the switch from (for example) cell proliferation to differentiation, with the hormone regulating a different or additional gene network in each case.

The real picture is no doubt more complicated than that uncovered to date. For example, several orphan receptors (and probably others that remain to be discovered) also form heterodimers with

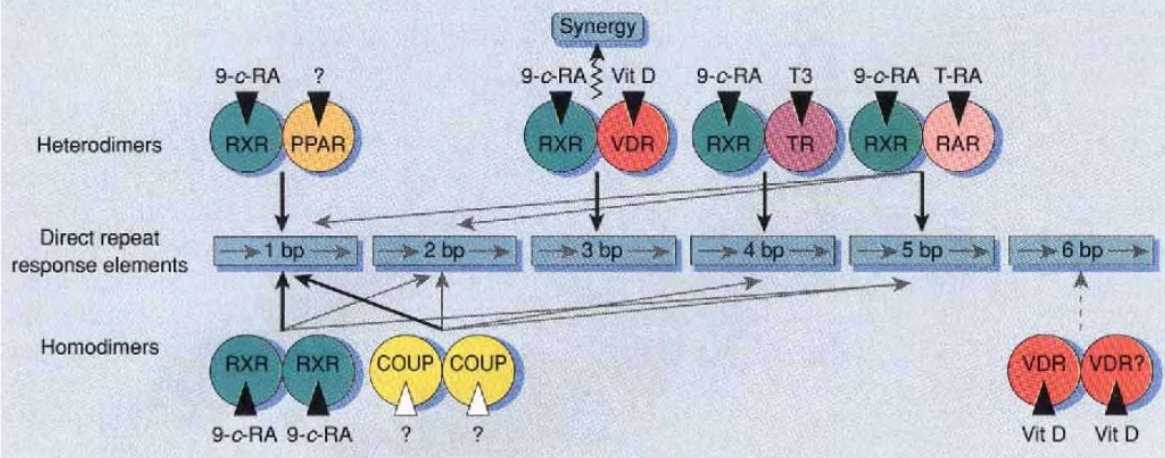

Promiscuous liaisons among the nuclear hormone receptor family. The various interactions are discussed in the text. RXR, receptor for 9-cis-retinoic acid (9-c-RA); PPAR, receptor activated by peroxisome proliferators and fatty acids ${ }^{4}$; VDR, vitamin $D$ receptor; TR, thyroid hormone receptor; RAR, receptor for trans-retinoic acid; COUP, chicken ovalbumin upstream promoter.

criptional activity of the heterodimer and this property could be regulated by 9 -cisretinoic acid. The new findings of Carlberg et al. ${ }^{1}$, and those of others ${ }^{16,19}$, support this second view. In the presence of both VDR and RXR, vitamin $\mathrm{D}_{3}$ and 9-cis-retinoic acid act synergistically on the osteopontin response element (DR3), whereas RXR or its ligand has no effect on the osteocalcin response element (DR6). Presumably, the ability of RXR to contribute to transcriptional activation of the heterodimer will depend upon the context of the response element within the promoter, and also the cell type, thus providing further fine tuning of the response $\mathrm{e}^{16,20}$.

The ability of several members of the nuclear hormone receptor superfamily to form heterodimers with RXR increases the combination of transcription factors that can have unique biological properties. However, this could mean that 9-cis-retinoic acid is a general permissive factor that acts synergistically with other ligands such as vitamin $\mathrm{D}_{3}$, all-trans retinoic acid and thyroid hormones to amplify the hormonal signal. So a cell that already contains 9-cis-retinoic acid would be exquisitely sensitive to the presence of the second hormone. That hormones such as vitamin $\mathrm{D}_{3}$ can work in two ways also provides a mechanism for regulating two gene networks. In the absence of 9-cis-retinoic acid both networks would respond similarly. However, in its presence, one network would be more sensitive to the second hormone and would achieve a greater maximal
RXR and the biological consequence of many receptors each competing for the attention of RXR is uncertain. In addition, other heterodimer combinations have been reported, for example between RAR and $T^{21}$, and some receptors interact weakly with their response elements as homodimers and monomers, suggesting that other signalling pathways exist $^{22}$

Stephen Green is at ZENECA Central Toxicology Laboratory, Alderley Park, Macclesfield, Cheshire SK10 4TJ, UK.

1. Carlberg, C. et al. Nature 361, 657-660 (1993)

2. Evans, R. M. Science 240, 889895 (1988).

3. O'Malley, B. W. \& Conneely, O. M. Molec. Endocr. 6, $1359-1361$ (1992).

4. Issemann, I. \& Green, S. Nature 347, 645-650 (1990)

5. Green, S. \& Chambon, P. Trends Genet. 4, 309-314 (1988).

6. Luisi, B. F. et al. Nature 352, 497-505 (1991)

7. Leid, M., Kastner, P. \& Chambon. P. Trends Biochem 17, 427-433 (1992).

8. Levin, A. A. et al. Nature 355, 359-361 (1992)

9. Heyman, R. A. et al. Cell 68, 397-406 (1992).

10. Yu, V. C. et al. Cell 67, 1251-1266 (1991)

11. Leid, M. et al. Cell 68, 377-395 (1992).

12. Zhang X K Hoffmann, B. Tran, P B V Graupner, G. \& Pfahi, M. Nature 355, 441-446 (1992).

13. Kliewer, S. A., Umesono, K., Manglesdorf, D. T. \&

14. Umesono, K. et al. Cell 65, 1255-1266 (1991)

15. Yao, T. P., Seagraves, W. A., Oro, A. E., McKeown, M. \& Evans, R. M. Cell 71, 63-72 (1992)

16. Durand, B., Saunders, M., Leroy, P., Leid, M \& Chambon, P. Cell 71, $73-85$ (1992)

17 Cooney, A. J Tsai, S. Y O'Malley, B. W. \& Tsai, M. J. Molec. cell. Biol. 12, 4153-4163 (1992).

18. Zhang. X. K. et al. Nature 358, 587-591 (1992).

19. Kliewer, S. A., Umesono, K., Noonan, D. J., Heyman, R. A. \& Evans, R. M. Nature 358, 771-774 (1992).

20. Nagpal, S. et al. Cell 70, 1007-1019 (1992)

21. Glass, C. K. et al. Cell 59, 697-708 (1989)

J. \& Samuels, H. H. Molec. Endocr. 6, 429-442 J. \& Sam Evans, R. M. Nature 355, 446-449 (1992)

22. Forman, B. M. Casanova, J., Raaka, B. M., Ghysdael,

\section{Stepping out}

SKATES and rays - a suborder (Rajoidea) of batoid fish - didn't take part in The Lobster Quadrille. If Lewis Carroll had known of the remarkable capacity of certain species for bipedal locomotion, however, he might well have invited them to join the dance. There have been allusions to such a capacity. But R. J. Holst and Q. Bone (Phil. Trans. R. Soc. B339, 105-108; 1993) now show by dissection of the pelvic fins and ciné photography of the fish in action that they can and do use limb-like parts of the fins for movement akin to walking. The authors include photos of the resulting tracks made in soft mud they suggest that rajids 'walk' when feeding on the bottom, for that form of motion enables their invertebrate prey to be located and captured most easily, and that their tracks may be evident in the fossil record.

\section{Water pump}

EXPERIMENTS at close to absolute zero have shown how light can push atoms around, but it seems that this has all been done before - five billion years ago when the Sun started to roast its protoplanetary nebula. H. I. Bloemink et al. have irradiated a tube of water vapour in a background of hydrogen with infrared radiation, and find that a concentration gradient builds up as the radiation presses harder on the $\mathrm{H}_{2} \mathrm{O}$ than on the background gas (Phys. Rev. Lett. 70, 742-745; 1993). Their aim was to explain the gradient of the deuterium/hydrogen ratio in the Solar System: the concentration ratio is $10^{-2}$ in Venus's atmosphere but $10^{-5}$ in Jupiter's. The hot, young Sun may have driven $\mathrm{H}_{2} \mathrm{O}$ away, the authors suggest, but not HDO, which responds less strongly to light. It remains to be seen whether planetary scientists will be swayed by the argument, given that more brute forces operated later in planetary atmospheres.

\section{More myosin}

PhyLogenetic analysis of the forcegenerating protein myosin reveals that there are at least three classes of the protein in eukaryotes $(\mathrm{H}$. V. Goodson and J. A. Spudich, Proc. natn. Acad. Sci. U.S.A. 90, 659-663; 1993). Myosin had been divided into two classes, I (singleheaded) and II (the better known twoheaded version). But the new analysis of amino-acid sequences shows that myosin I consists of a 'classic' type and a 'dilute' type, as divergent from each other as each is from myosin II. Further investigation may demonstrate that as many as seven classes of myosin I have evolved separately. In the myosin II class, Goodson and Spudich find that smooth muscle and striated muscle myosin were independently derived from non-muscle myosin. 